\title{
Protection of recombinant human erythropoietin toward rats with reduced- size liver transplantation for fatty liver.
}

\author{
Shunwu Chang*, Baochun Wang, Cexiong Fu, Xiaoguang Gong, Ning Liu, Yunfu Lv \\ Department of General Surgery, Hainan General Hospital, Haikou, Hainan, PR China
}

\begin{abstract}
Objective: This paper aims to discuss the protection of recombinant human erythropoietin (r-HuEPO) toward rats with reduced-size liver transplantation for fatty livers.

Methods: A total of 48 SD male rats were selected and fed with a high-fat diet to develop fatty liver. Later, the rats were divided into sham-operated, blank control (reduced sized liver transplantation +normal saline), positive control (reduced sized liver transplantation+VES), and study (reduced sized liver transplantation+r-HuEPO) groups, with 12 rats for each group. At 1 and $3 \mathrm{~d}$ of intervention, 6 rats from each group were sacrificed to test total bilirubin (TB), alanine aminotransferase (ALT), and aspartic transaminase (AST) levels in serum. Liver transplantation tissues were collected to test cell apoptosis and contents of tumor necrosis factor (TNF)- $\alpha$, superoxide dismutase (SOD), and malondialdehyde (MDA). The pathomorphism of liver transplantation tissues was observed $3 \mathrm{~d}$ after intervention.

Results: Except for SOCD content, the TB, ALT, and AST levels in serum, as well as TNF- $\alpha$ and MDA contents of the blank control and sham-operated groups at $3 \mathrm{~d}$, are significantly higher than those at $1 \mathrm{~d}$ $(p<0.05)$. By contrast, the indices of the research group and positive control group at day 3 are significantly lower than those at day $1(\mathbf{p}<0.05)$, whereas the SOD content at day 3 is markedly higher than that at day $1(\mathbf{p}<\mathbf{0 . 0 5})$. Significant inter-group differences $(\mathbf{p}<0.05)$ were observed. Cell apoptosis values in the positive control, blank control, and sham-operated groups at day 3 were notably higher than that at day $1(\mathbf{p}<0.05)$, but cell apoptosis in the research team at day 3 was similar to that at day 1 $(p>0.05)$. Significant inter-group differences $(p<0.05)$ were observed. Several small fat droplets can be observed in the research team, whereas hepatic sinusoids and hepatic lobules were clear and accompanied with certain necrosis of liver cells.

Conclusion: Through reduced-sized liver transplantation, r-HuEPO can significantly protect the liver functions of rats with fatty liver, relieve liver damage, and inhibit cell apoptosis, which may be related to the decreased TNF- $\alpha$ and MDA contents and increased SOD activity.
\end{abstract}

Keywords: r-HuEPO, Fatty liver, Reduced sized liver transplantation, Rat.

Accepted on February 08, 2018

\section{Introduction}

Fatty liver is a kind of pathologic change in the liver caused by excessive fat accumulation in hepatocytes. The disease causes serious threat to human life and health. Fatty liver is caused by obesity, alcohol, diabetes, drugs, and other factors [1,2]. Recently, the morbidity of fatty liver in China has steadily increased and has occurred in younger populations. As an exogenous erythropoietin (EPO), the recombinant human erythropoietin (r-HuEPO) performs numerous functions, such as mitogenic, anti-apoptosis, anti-inflammatory, angiogenesis promotion, and tissue protection [3]. Several studies reported that EPO can protect the brain, heart, liver, and kidney [4]. However, research on the protection of r-HuEPO in reducedsize liver transplantation for fatty liver is limited. To investigate the protection of r-HuEPO in rats with reduced-size liver transplantation for fatty liver, rats were fed with a high-fat diet to develop fatty liver. Then, the rats were randomly classed into four groups. All groups except the sham-operated group were treated by reduced-size liver transplantation. The blank control, positive control, and study groups were additionally treated with normal saline, VES, and r-HuEPO. Related indices were observed. Results are introduced in the following text.

\section{Information and Methods}

\section{Test animals and reagents}

A total of 48 healthy male Sprague-Dawley rats weighing 200-250 g were bought from the Experimental Animal Center of Zhejiang Academics of Medical Sciences. In the experiment, the rats were reared in a sterile, constanttemperature environment. 
r-HuEPO was bought from Shanghai Luoshi Company. VES was purchased from Zhejiang Anglikang Pharmaceutical Co. Ltd. Normal saline was bought from Procell Life Science \& Technology Co., Ltd. SOD and MDA kits were bought from Nanjing Jiancheng Biology Engineering Institute. Enzymelinked immunosorbent assay kit was bought from Shanghai UNIV Biology Co., Ltd. TUNEL kit was purchased from Nanjing KeyGen Biotech Company.

\section{Methods}

\section{Establishment of rat fatty liver model}

SD male rats were fed with a high-fat diet for 12 weeks successively to develop moderate and severe fatty liver models.

\section{Grouping and treatment}

After fatty liver models were established, the 48 rats were randomly classified into sham-operated, blank control, positive control, and study groups, with 12 rats in each group. Except for the sham-operated group, the other groups were subjected to intervention by reduced-size liver transplantation by the two-cuff technique.

Rats were disinfected conventionally and anesthetized. Then, the rats were fixed on a rat board horizontally and sliced at the middle of the abdomen from the processus xiphoideus to the symphysis pubis to completely expose the liver. Oxygen mask inspiration was given.

The intestinal canal was covered by wet gauze. We separated, ligated, and cut the right vein, superior and inferior venae cavae, right upper gland vena superior, free common bile duct, left liver to the esophageal blood vessel and portal vein, and removed the primary liver. The supplied liver was placed at the right location and all venous blood vessels were sutured sequentially.

Then, normal saline was used for rinsing to eliminate blood and blood clots in the veins. Venous sleeve tube was inserted into the supplied liver quickly, ligated, and fixed. A support tube was inserted into the common bile duct for ligature and fixation.

Then, the liver was covered with the omentum majus, and normal saline with penicillin was injected into the abdomen. Finally, the abdomen was closed.

Immediately after the liver transplantation, the blank control, positive control, and study groups were intravenously injected with $1.5 \mathrm{~mL}$ normal saline, $4000 \mathrm{U} / \mathrm{kg} \mathrm{VES}$, and $5000 \mathrm{U} / \mathrm{kg} \mathrm{r}$ HuEPO, respectively.

\section{Test method of TB, ALT, and AST levels in serum}

Six rats from each group were sacrificed at days 1 and 3 . Serum was collected to test TB, ALT, and AST levels through the enzymatic method using a fully automatic biochemical analyzer.

\section{Cell apoptosis test in liver transplantation tissue (TUNEL method)}

Tissue samples were collected from rats from all groups and processed by conventional paraffin section, dewaxing, and dehydration. Cell apoptosis in liver tissues was tested according to specifications of the in-situ apoptosis kit.

\section{Test method of TNF- $\alpha, S O D$ and MDA contents}

Tissue samples were collected from rats of all four groups, prepared into $10 \%$ liver homogenate, and centrifuged. Then, $0.1 \mathrm{~mL}$ supernatant was collected for testing TNF- $\alpha$, SOD, and MDA contents by ELISA, spectrophotometry, and thiobarbituric acid method, respectively.

\section{Pathological examination method of liver transplantation tissues (hematoxylin-eosin and $\mathrm{HE}$ staining)}

Liver transplantation tissue samples at 3 days were collected and fixed by $10 \%$ formaldehyde. The samples were processed by conventional paraffin embedding, sectioning, and $\mathrm{HE}$ staining. Pathologic changes of liver plantation tissues were observed under a microscope.

\section{Observation indexes}

Cell apoptosis of liver transplantation tissues at days 1 and 3 were observed. Most cells from normal liver tissues were negative in TUNEL staining and the cell nuclei were blue. Apoptotic cells were positive in TUNEL staining, and the cell nuclei were brown. Under the microscope, cells under $10 \mathrm{hpf}$. in each section piece were counted to calculate the number of apoptotic cells and apoptosis rate. Apoptosis rate=number of apoptotic cells/total counted cells $\times 100 \%$.

Pathological changes, which mainly included hepatocytes, hepatic lobule, fat droplet, and hepatic sinusoid, in liver plantation tissues of different groups were observed at day 3 .

\section{Statistical analysis}

Statistical analysis of the data was performed using SPSS18.0. Two-sample measurement data were verified by t-test, and multi-sample measurement data were verified by one-way analysis of variance. $\mathrm{p}<0.05$ reflects statistically significant difference.

\section{Results}

\section{Comparison of TB, ALT and AST levels in serum of different groups at 1 and $3 d$}

For all four groups, significant differences in TB, ALT, and AST levels in serum were observed between days 1 and 3 $(p<0.05)$. Different groups showed notably different TB, ALT, and AST levels in serum $(\mathrm{p}<0.05)$. The sham-operated group showed the highest TB, ALT, and AST levels in serum, 
followed by the blank control group, positive control group, and the study group in succession (Table 1).

\section{Comparison of cell apoptosis in liver transplantation tissues at 1 and $3 d$}

Significant differences were observed among four groups in terms of cell apoptosis at days 1 and $3(p<0.05)$. Cell apoptosis in the study group at day 3 was similar to that at day 1 $(p>0.05)$. However, significant intra-group differences in cell apoptosis were seen at days 1 and $3(\mathrm{p}<0.05)$. The shamoperated group achieved the highest apoptosis index, followed by the blank control group, positive control group, and the study group in succession (Table 2).

\section{Comparison of TNF- $\alpha, S O D$, and MDA contents of different groups at 1 and 3 days}

Statistically significant differences were found among four groups in terms of TNF- $\alpha$, SOD, and MDA contents at days 1 and $3(\mathrm{p}<0.05)$. Moreover, significant differences in TNF- $\alpha$, SOD, and MDA contents were observed in the same group between days 1 and $3(p<0.05)$. Except for SOD content, the sham-operated group presented the highest TNF- $\alpha$ and MDA, successively followed by the blank control group, negative control group, and study group (Table 3).

Table 1. Comparison of TB, ALT and AST levels in serum of different groups at 1 and $3 d$.

\begin{tabular}{|c|c|c|c|c|c|c|c|c|c|c|c|c|c|c|c|c|c|c|c|}
\hline \multirow{2}{*}{ Groups } & \multirow{2}{*}{$\mathbf{n}$} & \multicolumn{4}{|c|}{ TB ( $\mu \mathrm{mol} / \mathrm{L})$} & \multirow{2}{*}{$\frac{t}{1 d}$} & \multirow{2}{*}{$\mathbf{p}$} & \multicolumn{3}{|c|}{ ALT (U/L) } & \multicolumn{2}{|r|}{$\mathbf{t}$} & \multirow[t]{2}{*}{$\mathbf{p}$} & \multicolumn{3}{|c|}{ AST (U/L) } & & \multirow{2}{*}{$\mathbf{t}$} & \multirow[t]{2}{*}{$\mathbf{p}$} \\
\hline & & $1 \mathrm{~d}$ & & $3 d$ & & & & $3 d$ & & $1 \mathrm{~d}$ & & $3 \mathrm{~d}$ & & & & & & & \\
\hline $\begin{array}{l}\text { Study } \\
\text { group }\end{array}$ & 6 & $\begin{array}{l}28.47 \\
2.24\end{array}$ & \pm & $\begin{array}{l}23.19 \\
3.09\end{array}$ & \pm & 3.389 & 0.007 & $\begin{array}{l}356.34 \\
42.14\end{array}$ & \pm & $\begin{array}{l}276.35 \\
32.18\end{array}$ & \pm & 3.695 & 0.004 & $\begin{array}{l}401.27 \\
39.68\end{array}$ & \pm & $\begin{array}{l}308.67 \\
28.39\end{array}$ & \pm & 4.649 & 0.001 \\
\hline $\begin{array}{l}\text { Positive } \\
\text { control } \\
\text { group }\end{array}$ & 6 & $\begin{array}{l}33.56 \\
4.18^{a}\end{array}$ & \pm & $\begin{array}{l}27.65 \\
3.58^{a}\end{array}$ & \pm & 2.63 & 0.025 & $\begin{array}{l}498.27 \\
51.64^{a}\end{array}$ & \pm & $\begin{array}{l}387.34 \\
47.25^{a}\end{array}$ & \pm & 3.822 & 0.003 & $\begin{array}{l}487.69 \\
40.25^{a}\end{array}$ & \pm & $\begin{array}{l}376.98 \\
31.47^{a}\end{array}$ & \pm & 5.308 & 0 \\
\hline $\begin{array}{l}\text { Blank } \\
\text { control } \\
\text { group }\end{array}$ & 6 & $\begin{array}{l}42.89 \\
6.46^{a b}\end{array}$ & \pm & $\begin{array}{l}102.47 \\
6.38^{a b}\end{array}$ & \pm & 16.074 & 0 & $\begin{array}{l}621.35 \\
60.54^{\mathrm{ab}}\end{array}$ & \pm & $\begin{array}{l}894.57 \\
37.27^{a b}\end{array}$ & \pm & 9.414 & 0 & $\begin{array}{l}654.28 \\
56.38^{a b}\end{array}$ & \pm & $\begin{array}{l}907.36 \\
76.41^{a b}\end{array}$ & \pm & 6.528 & 0 \\
\hline $\begin{array}{l}\text { Sham- } \\
\text { operated } \\
\text { group }\end{array}$ & 6 & $\begin{array}{l}58.39 \\
6.97^{a b c}\end{array}$ & \pm & $\begin{array}{l}143.87 \\
5.68^{a b c}\end{array}$ & \pm & 23.287 & 0 & $\begin{array}{l}724.31 \\
62.58^{a b c}\end{array}$ & \pm & $\begin{array}{l}1023.87 \\
63.24^{a b c}\end{array}$ & \pm & 8.247 & 0 & $\begin{array}{l}768.39 \\
64.25^{a b c}\end{array}$ & \pm & $\begin{array}{l}1245.37 \\
86.21^{a b c}\end{array}$ & \pm & 10.867 & 0 \\
\hline $\mathrm{F}$ & & 7.956 & & 11.398 & & I & I & 8.671 & & 9.876 & & I & I & 6.374 & & 5.741 & & I & I \\
\hline $\mathrm{p}$ & & 0 & & 0 & & I & I & 0 & & 0 & & I & 1 & 0 & & 0 & & I & I \\
\hline
\end{tabular}

Notes: ${ }^{a} p<0.05$ for comparison with the study group; ${ }^{b} p<0.05$ for comparison with the positive control group; ${ }^{c} p<0.05$ for comparison with the blank control group.

Table 2. Comparison of cell apoptosis in liver transplantation tissues at 1 and 3 d.

\begin{tabular}{|c|c|c|c|c|c|}
\hline Groups & $\mathbf{n}$ & Apoptosis index at $1 \mathrm{~d}(\%)$ & Apoptosis index at $3 \mathrm{~d}(\%)$ & $\mathbf{T}$ & $\mathbf{p}$ \\
\hline Study group & 6 & $15.17 \pm 1.38$ & $16.47 \pm 2.67$ & 1.059 & 0.314 \\
\hline Positive control group & 6 & $19.68 \pm 3.27^{a}$ & $23.98 \pm 3.14^{\mathrm{a}}$ & 2.323 & 0.043 \\
\hline Blank control group & 6 & $28.69 \pm 4.78^{\mathrm{ab}}$ & $39.67 \pm 4.22^{\mathrm{ab}}$ & 4.218 & 0 \\
\hline Sham-operated group & 6 & $37.47 \pm 6.97^{\mathrm{abc}}$ & $46.38 \pm 5.39^{\mathrm{abc}}$ & 2.477 & 0.033 \\
\hline $\mathrm{F}$ & & 3.278 & 4.397 & I & I \\
\hline$p$ & & 0.001 & 0 & l & l \\
\hline
\end{tabular}

Notes: ${ }^{a} p<0.05$ for comparison with the study group; ${ }^{b} p<0.05$ for comparison with the positive control group. ${ }^{c} p<0.05$ for comparison with the blank control group.

Table 3. Comparison of TNF- $\alpha$, SOD and MDA contents of different groups at 1 and $3 d$.

\begin{tabular}{|c|c|c|c|c|c|c|c|c|c|c|c|c|c|c|c|}
\hline \multirow{2}{*}{ Groups } & \multirow{2}{*}{$\mathbf{n}$} & \multicolumn{2}{|c|}{ TNF- $\alpha(p g / m L)$} & \multirow{2}{*}{$\frac{t}{1 \mathrm{~d}}$} & \multirow{2}{*}{$\mathbf{p}$} & \multicolumn{3}{|c|}{ SOD (U/mL) } & \multirow{2}{*}{$\frac{t}{3 d}$} & \multirow[t]{2}{*}{$\mathbf{p}$} & \multicolumn{3}{|c|}{ MDA (nmol/mL) } & \multirow{2}{*}{$\mathbf{t}$} & \multirow[t]{2}{*}{$\mathbf{p}$} \\
\hline & & $1 d$ & $3 d$ & & & $3 \mathrm{~d}$ & & $1 \mathrm{~d}$ & & & & & & & \\
\hline Study group & 6 & $\begin{array}{l}67.38 \\
12.36\end{array}$ & $\begin{array}{ll} \pm & 42.68 \\
& 7.32\end{array}$ & $\pm \quad 4.212$ & 0.002 & $\begin{array}{l}63.74 \\
6.33\end{array}$ & \pm & $76.69 \pm 7.01$ & 3.358 & 0.007 & $\begin{array}{l}23.65 \\
5.37\end{array}$ & \pm & $14.38 \pm 3.58$ & 3.518 & 0.006 \\
\hline
\end{tabular}




\begin{tabular}{|c|c|c|c|c|c|c|c|c|c|c|c|c|c|c|c|c|c|c|}
\hline $\begin{array}{l}\text { Positive } \\
\text { control } \\
\text { group }\end{array}$ & 6 & $\begin{array}{l}96.28 \\
11.69^{a}\end{array}$ & \pm & $\begin{array}{l}65.69 \\
8.01^{a}\end{array}$ & \pm & 5.288 & 0 & $\begin{array}{l}54.69 \\
6.36^{a}\end{array}$ & \pm & $\begin{array}{l}63.98 \\
7.27^{a}\end{array}$ & \pm & 2.356 & 0.04 & $\begin{array}{l}31.64 \\
6.38 a\end{array}$ & $\begin{array}{r}22.49 \\
5.33 a\end{array}$ & \pm & 2.696 & 0.022 \\
\hline $\begin{array}{l}\text { Blank } \\
\text { control } \\
\text { group }\end{array}$ & 6 & $\begin{array}{l}131.39 \\
24.13^{a b}\end{array}$ & \pm & $\begin{array}{l}159.88 \\
13.67^{a b}\end{array}$ & \pm & 2.561 & 0.031 & $\begin{array}{l}47.21 \\
5.17^{a b}\end{array}$ & \pm & $\begin{array}{l}39.86 \\
4.52^{\mathrm{ab}}\end{array}$ & \pm & 2.622 & 0.026 & $\begin{array}{l}48.69 \\
7.57 a b\end{array}$ & $\begin{array}{ll} & 58.39 \\
& 6.24 a b\end{array}$ & \pm & 2.422 & 0.036 \\
\hline $\begin{array}{l}\text { Sham- } \\
\text { operated } \\
\text { group }\end{array}$ & 6 & $\begin{array}{l}161.28 \\
16.34^{a b c}\end{array}$ & \pm & $\begin{array}{l}187.69 \\
17.23^{a b c}\end{array}$ & \pm & 2.724 & 0.021 & $\begin{array}{l}37.28 \\
4.98^{a b c}\end{array}$ & \pm & $\begin{array}{l}28.97 \\
5.81^{a b c}\end{array}$ & \pm & 2.66 & 0.024 & $\begin{array}{l}63.28 \\
8.66 a b c\end{array}$ & $\begin{array}{l} \pm 79.68 \\
7.39 a b c\end{array}$ & \pm & 3.529 & 0.005 \\
\hline$F$ & & 6.321 & & 5.278 & & 1 & I & 4.396 & & 5.037 & & I & 1 & 3.986 & 8.124 & & 1 & 1 \\
\hline$P$ & & 0 & & 0 & & I & I & 0 & & 0 & & I & 1 & 0 & 0 & & I & I \\
\hline
\end{tabular}

Notes: ${ }^{a} p<0.05$ for comparison with the study group; ${ }^{b} p<0.05$ for comparison with the positive control group; ${ }^{c} p<0.05$ for comparison with the blank control group.

\section{Pathological section of liver transplantation tissues of different groups at $3 \mathrm{~d}$}

Pathological sections of liver transplantation tissues of different groups at day 3 are shown in Figures 1 and 2.
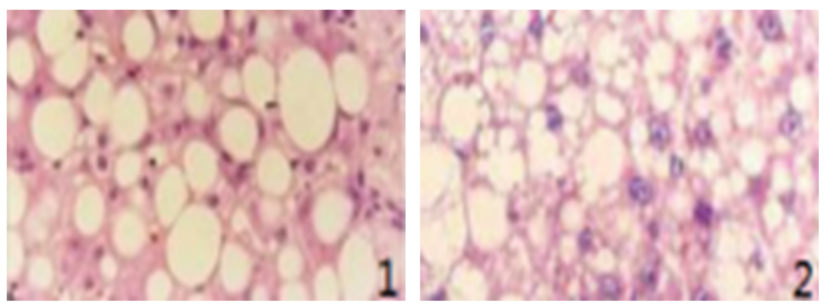

Figure 1. (1) Sham-operated group: unclear hepatic lobule, abundant large-bubble fat droplets, ambiguous hepatic sinusoid, and evident necrosis of liver cells; (2) Blank control group: abundant unevenbubble fat droplets, inflammatory cell infiltration of the hepatic lobule, and necrosis of liver cells.
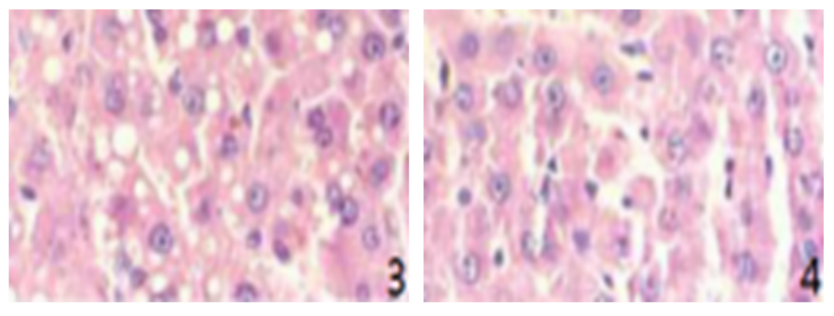

Figure 2. (3) Positive control group: relatively increased smallbubble fat droplets, visible hepatic sinusoid, accompanied with necrosis of liver cells; (4) Study group: clear hepatic sinusoid, few small-bubble fat droplets, normal structure of hepatic lobule, accompanied with certain necrosis of liver cells.

\section{Discussion}

Light fatty liver generally presents no clinical symptoms. Moderate and severe fatty liver causes tiredness, weakness, poor appetite, nausea, emesis, and dull pains in the right upper abdomen or liver zone. Excessive depositions of fats in liver will further cause fever and acute pain or pressing pain on the right upper abdomen. Without active treatment, fatty liver will developed into hepatitis, hepatic sclerosis, or even liver cancer [5]. Therefore, fatty liver should be treated positively and according to standard after diagnosis to prevent lesions. r-
HuEPO can simulate erythropoiesis and is mainly used for anemia therapy and achieved outstanding effect. Moreover, r$\mathrm{HuEPO}$ is a multifunctional cytokine with anti-inflammatory, anti-oxidative, tissue damage relieving, and apoptosis inhibitory functions [6]. Reportedly, r-HuEPO can inhibit the activity of nuclear transcription factor (NF-kB) and the expression of iNOS and inhibit the release of NO, thereby relieving cytotoxic effects and inflammatory reactions and reducing damages to the liver and the TNF- $\alpha$, ALT, and AST levels. This cytokine can protect liver functions.

TB, ALT, and AST are all measures for liver functions that are sensitive to liver damage and damage degree. Clinically, liver functional indices are often tested to detect liver damage. Growths of TB, ALT, and AST represent hepatocyte damage or necrosis [7]. Growths of TB, ALT, and AST can be detected in fatty liver, alcoholic hepatitis, hepatitis, hepatic sclerosis, jaundice, and cholelithiasis. In this study, TB, ALT, and AST levels in the serum of the study group at days 1 and 3 were significantly lower than those of the positive control, blank control, and sham-operated groups $(\mathrm{p}<0.05)$. The TB, ALT, and AST levels in the serum of the study group at day 3 were significantly lower than those at day $1(\mathrm{p}<0.05)$. This finding indicated that $\mathrm{r}-\mathrm{HuEPO}$ intervention can reduce TB, ALT, and AST levels in serum in rats with reduced-size liver transplantation.

MDA is the main product of membrane lipid peroxidation and can intensify membrane damage. High MDA content implies serious cell oxidative stress, which indirectly reflects intensifying cell damage [8]. SOD is an important anti-oxidase in living organisms and can intercept oxygen radicals to relieve cell damage and repair damaged cells [9]. As an important inflammatory cytokine, TNF- $\alpha$ participates in inflammatory responses in the body and causes cell damages and tissue necrosis [10]. In this study, TNF- $\alpha$ and MDA contents of the study group at days 1 and 3 were significantly lower than those of the positive control, blank control, and sham-operated groups $(p<0.05)$. The TNF- $\alpha$ and MDA contents of the study group at day 3 were notably lower than those at day 1 $(p<0.05)$. The SOD content of the study group at days 1 and 3 were significantly higher than those of other groups $(p<0.05)$, with the content at day 3 substantially exceeding that of day 1 $(p<0.05)$. These outcomes imply that $r-H u E P O$ intervention 
after reduced-size liver transplantation for fatty liver can reduce TNF- $\alpha$ and MDA contents and increase SOD content significantly.

Moreover, the apoptosis index of the study group at days 1 and 3 was considerably lower than those of the other three groups $(p<0.05)$. The apoptosis index of the study group at day 3 was similar to that at day $1(\mathrm{p}>0.05)$, indicating that $r-\mathrm{HuEPO}$ intervention after reduced-size liver transplantation for fatty liver can decrease the apoptosis index significantly. Compared with the sham-operated, blank control, and positive control groups, the study group showed lighter cell necrosis and notably smaller quantity of fat droplets, but presented relatively normal hepatic lobule and hepatic sinusoid structure. Therefore, r-HuEPO intervention after reduced-size liver transplantation for fatty liver can relieve damage to the liver tissues and decrease liver cell necrosis effectively.

\section{Conclusion}

r-HuEPO intervention after reduced-size liver transplantation for fatty liver can lower TB, ALT, and AST levels in serum significantly, inhibit the expression levels of TNF- $\alpha$ and MDA, increase SOD content, decrease apoptosis index, and protect liver functions markedly. This work provides theoretical references for the clinical application of r-HuEPO to patients with reduced-size liver transplantation for fatty liver and is worth promoting.

\section{Acknowledgment}

This work was supported by grants from the Natural Science Foundation of Hainan (No. 20158353).

\section{References}

1. Jaruvongvanich V, Sanguankeo A, Upala S. Non-alcoholic fatty liver disease is not associated with thyroid hormone levels and hypothyroidism: A Systematic review and metaanalysis. Eur Thyroid 2017; 6: 208-215.

2. Yu G, Hua ZH, Li Z, Wei LT. Hepatocyte growth factor shows benefits for patients with chronic renal failure induced type 2 diabetes. Biomed Res-India 2017; 28: 3837-3844.

3. Mirmiran P, Amirhamidi Z, Ejtahed HS. Relationship between diet and non-alcoholic fatty liver disease: a review article. Iran J Public Health 2017; 46: 1007-1017.
4. Tagliari MP, Stulzer HK, Assreuy J, Bresolin TMB, Silva MAS. Evaluation of physicochemical characteristics of suspensions containing hydrochlorothiazide developed for pediatric use. Lat Am J Pharm 2009; 28: 734-740.

5. Simcox J, Geoghegan G, Maschek JA. Global analysis of plasma lipids identifies liver-derived acylcarnitines as a fuel source for brown fat thermogenesis. Cell Metab 2017; 26: 509-522.

6. Guo N, Lin G. Effects of nonsurgical periodontal therapy on serum inflammatory factor levels in patients with chronic kidney disease and periodontitis. Biomed Res-India 2017; 28: 3899-3902.

7. Behrouz V, Jazayeri S, Aryaeian N. Effects of probiotic and prebiotic supplementation on leptin, adiponectin, and glycemic parameters in non-alcoholic fatty liver disease: a randomized clinical trial. Middle East J Dig Dis 2017; 9: 150-157.

8. Klisic A, Kavaric N, Jovanovic M, Soldatovic I. Bioavailable testosterone is independently associated with fatty liver index in postmenopausal women. Arch Med Sci 2017; 13: 1188-1196.

9. Soliman II, Afify EA, Shobragi GAL. Evaluation of extemporaneous pediatric gabapentin suspension prepared from gabapentin capsules. Lat Am J Pharm 2014; 33: 746-752.

10. Jeong WK. Hepatic and splenic volumetry could be used as an imaging parameter to evaluate fibrosis grades of the diffuse liver disease including non-alcoholic fatty liver disease. Gut Liver 2017; 11: 577-578.

\section{*Correspondence to}

Shunwu Chang

Department of General Surgery

Hainan General Hospital

Haikou

Hainan

PR China 